\title{
Trajetórias Migratórias na Voz dos Sujeitos, Trabalhadores do Setor Sucroalcooleiro em Ituiutaba, Minas Gerais
}

\author{
Migratory Trajectories in the Voice of the Subjects, Workers in the Sugar Alcohol \\ Sector in Ituiutaba, Minas Gerais
}

Trayectorias Migratorias en la Voz de los Sujetos, Trabajadores del Sector Azúcar y Alcohol en Ituiutaba, Minas Gerais

\author{
Daniel Féo Castro de Araújo ${ }^{1}$ \\ https://orcid.org/ 0000-0001-6345-346X \\ Fernando Luiz Araújo Sobrinho ${ }^{2}$ \\ https://orcid.org/ 0000-0003-1815-8677
}

RESUMO: O objetivo deste artigo é compreender a realidade dos (as) trabalhadores nordestinos no município de Ituiutaba (MG), para isto a análise se volta para a abordagem das trajetórias migratórias dos canavieiros. Nesse contexto, as narrativas deles foram fundamentais ao permitir reconstituir motivações, causas e desdobramentos. A partir da coleta de histórias de vida através de entrevistas e do uso da oralidade como ferramenta metodológica se entende como os relatos são essenciais para a compreensão desta modalidade migratória. Para alcançar os resultados desta pesquisa foi utilizada uma metodologia qualitativa composta por levantamento bibliográfico inerente ao tema e entrevistas semiestruturadas com trabalhadores migrantes nordestinos residentes no município de Ituiutaba, Minas Gerais. Destaca-se que as entrevistas bem como a identificação dos sujeitos e o uso de suas falas foi autorizado através de assinatura de termo de consentimento. A maioria dos entrevistados ocupa direta e indiretamente postos de trabalhos relacionados ao setor sucroalcooleiro. Como um dos principais resultados da pesquisa, foi possível constatar atributos e características da origem, as motivações para o engajamento no movimento migratório, redes geográficas envolvendo diversas localidades de origem e destino, bem como contatos sociais que viabilizaram as migrações, e as intenções e perspectivas para o futuro dos migrantes nordestinos residentes em Ituiutaba, Minas Gerais.

PALAVRAS-CHAVE: Migrantes. Nordestinos. Realidade. Ituiutaba.

\begin{abstract}
The objective of this article is to understand the reality of the northeastern workers in the municipality of Ituiutaba (MG), for this, the analysis turns to the approach of the migratory trajectories

\footnotetext{
${ }^{1}$ Doutorando em Geografia - UNB. E-mail: daniel.feo@gmail.com.

${ }^{2}$ Doutorado em Geografia - Universidade Federal de Uberlândia. Professor do Departamento de Geografia da UNB. E-mail: flasobrinho@gmail.com.
} 
of the sugarcane. In this context, their narratives were fundamental in allowing the reconstruction of motivations, causes and consequences. From the collection of life stories through interviews and the use of orality as a methodological tool, it is understood how the reports are essential for the understanding of this migratory modality. To achieve the results of this research, a qualitative methodology was used, consisting of a bibliographic survey inherent to the theme and semi-structured interviews with northeastern migrant workers living in the municipality of Ituiutaba, Minas Gerais. It is noteworthy that the interviews as well as the identification of the subjects and the use of their speeches were authorized by signing a consent form. Most respondents directly and indirectly occupy jobs related to the sugar and alcohol sector. As one of the main results of the research, it was possible to verify the attributes and characteristics of the origin, the motivations for engaging in the migratory movement, geographic networks involving different locations of origin and destination, as well as social contacts that made migration possible, and the intentions and perspectives for the future of northeastern migrants residing in Ituiutaba, Minas Gerais.

KEYWORDS: Migrants. Northeasterners. Reality. Ituiutaba.

RESUMEN: El objetivo de este artículo es comprender la realidad de los trabajadores del noreste en el municipio de Ituiutaba (MG), para esto, el análisis gira en torno al enfoque de las trayectorias migratorias de la caña de azúcar. En este contexto, sus narraciones fueron fundamentales para permitir la reconstrucción de motivaciones, causas y consecuencias. Desde la recopilación de historias de vida a través de entrevistas y el uso de la oralidad como herramienta metodológica, se entiende cómo los informes son esenciales para la comprensión de esta modalidad migratoria. Para lograr los resultados de esta investigación, se utilizó una metodología cualitativa, que consiste en una encuesta bibliográfica inherente al tema y entrevistas semiestructuradas con trabajadores migrantes del noreste de la ciudad de Ituiutaba, Minas Gerais. Es de destacar que las entrevistas, así como la identificación de los sujetos y el uso de sus discursos fueron autorizados mediante la firma de un formulario de consentimiento. La mayoría de los encuestados ocupan directa e indirectamente trabajos relacionados con el sector del azúcar y el alcohol. Como uno de los principales resultados de la investigación, fue posible verificar los atributos y características del origen, las motivaciones para participar en el movimiento migratorio, las redes geográficas que involucran diferentes ubicaciones de origen y destino, así como los contactos sociales que hicieron posible la migración, y las intenciones y perspectivas para el futuro de los migrantes del noreste que residen en Ituiutaba, Minas Gerais.

PALABRAS CLAVE: Migrantes. Los del noreste. Realidad. Ituiutaba.

\section{INTRODUÇÃO}

O município de Ituiutaba localiza-se na Mesorregião do Triângulo Mineiro/Alto Paranaíba e transformou-se numa das principais regiões produtoras de cana-de-açúcar do estado de Minas Gerais, constituindo uma área plantada com cana-de-açúcar que aumentou de 14.135 hectares no ano 2005 para 68.667 hectares no ano de 2010 e 87.544 hectares em 2014, segundo o Instituto Brasileiro de Geografia e Estatística (IBGE, 2014). Na figura 1 pode ser analisada a localização de Ituiutaba, em relação ao estado de Minas Gerais.

Segundo Silva e Santos (2015), as transformações no setor da agroindústria canavieira acontecem desde o começo de 1990, início da desregulamentação do Proálcool, o que acarretou a livre concorrência dos preços em que os personagens do setor buscavam dar uma sobrevida ao programa. Assim, a retomada do crescimento no setor veio com a 
produção dos biocombustíveis e o etanol brasileiro passou a ser competitivo no mercado mundial.

Figura 1 - Microrregião Geográfica de Ituiutaba/MG
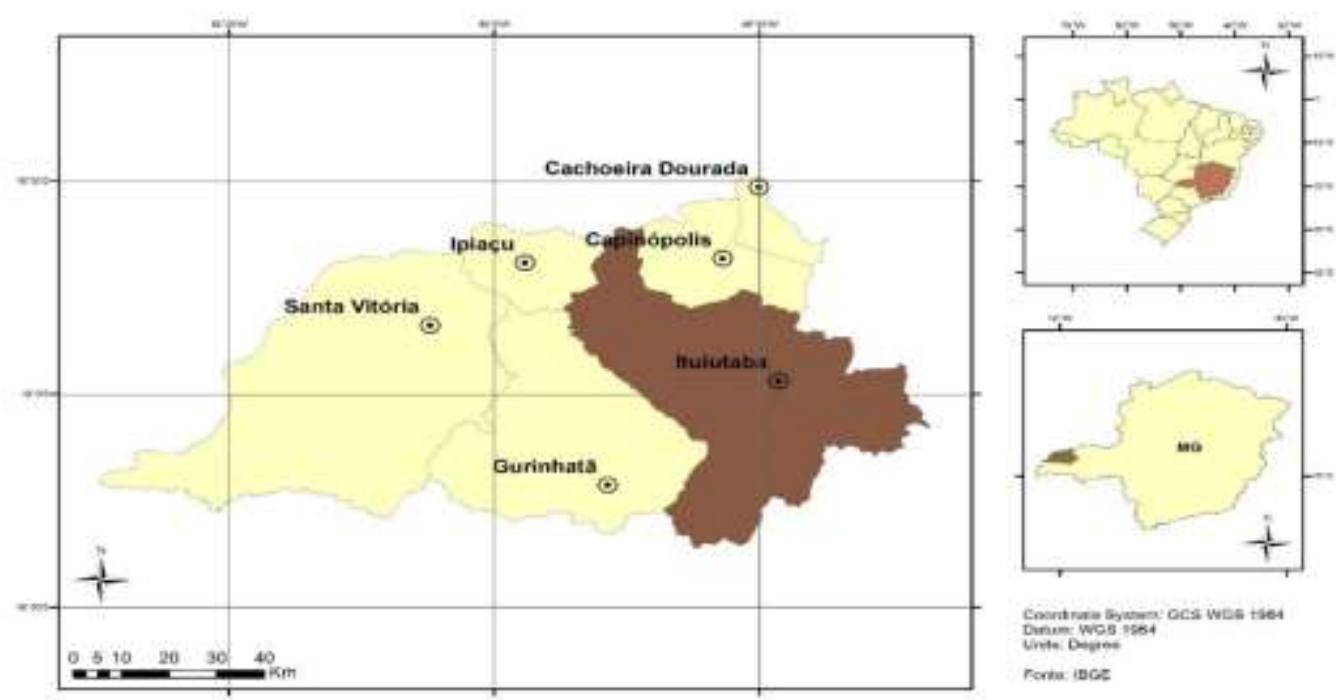

Fonte: Dados da pesquisa, elaborado por C. J. Maciel (2013).

De maneira especial, na última década, houve grande estímulo à produção de etanol, principalmente pelo surgimento dos veículos bicombustíveis (flex) em 2003 e 2004, capazes de utilizar qualquer combinação de gasolina e etanol, o que elevou significativamente a demanda interna por etanol hidratado. Com a elevação do preço do barril de petróleo, a intensificação das discussões sobre o aquecimento global e o papel dos combustíveis fósseis na problemática ambiental gerou-se uma alteração decisiva sobre as perspectivas do setor sucroenergético (ARAÚJO; ARAÚJO SOBRINHO, 2020).

O início dos anos 2000 foi marcado por um período expansivo das atividades do setor sucroalcooleiro, em decorrência da ampliação do mercado internacional para o açúcar e etanol, assim como do crescimento da demanda interna e externa por este combustível, em função da introdução dos veículos flexfuel no período do Governo Luiz Inácio Lula da Silva (2003-2011) (LAGO, 2010). A expressiva ampliação das atividades se explica por meio do aumento dos investimentos, da ampliação da área produtora, o desenvolvimento da estrutura produtiva, assim como por meio do tamanho da população ocupada nos seus serviços de forma direta e indireta. Portanto, em função do aumento da mão de obra migrante neste setor produtivo e no recorte territorial em destaque, se reitera a relevância da temática deste artigo.

Como desdobramento dessas condições, inicia-se o processo de expansão da produção para outras regiões do país, dentre as quais a microrregião de Ituiutaba/MG, pela 
qual passa a ser o lugar da territorialização de grandes grupos nacionais e internacionais por meio das unidades produtoras de açúcar, etanol e energia.

As condições naturais, políticas e econômicas existentes no Triângulo Mineiro o transformaram em uma nova fronteira agrícola da cana-de-açúcar, principalmente na Microrregião de Ituiutaba, onde o cultivo aparece como um dos principais setores da economia. Nesse contexto, a expansão da cana-de-açúcar pelas áreas do Cerrado mineiro atingiu o município de Ituiutaba em 1990 (ARAÚJO, 2018).

A dimensão espacial dos trabalhadores agrícolas é componente imprescindível do mercado de trabalho do complexo setor energético no Brasil (SILVA, 2007). O Triângulo Mineiro, principal área produtora de cana-de-açúcar no Estado de Minas Gerais, se destaca ainda na esfera dessa dimensão (CLEPS JÚNIOR, 2009). Os canavieiros vindos de algumas das regiões mais pobres do Brasil como o interior nordestino se destinam às regiões produtoras, respondendo à demanda por trabalhadores pouco qualificados nessa atividade (SILVA; SANTOS, 2014).

Esta dinâmica contém três dimensões primordiais: a combinação com a ampliação das atividades do setor sucroenergético na primeira década de 2000 (RAMOS; LUCHIARI JÚNIOR, 2008), a relevância no contexto da força de trabalho agrícola no Brasil (BACCARIN, 2002), e as intenções de extinção de postos de emprego no início deste século.

As atividades relacionadas à produção de cana-de-açúcar concentram a maioria dos assalariados agrícolas no Brasil, e na microrregião de Ituiutaba, Minas Gerais é a atividade que mais emprega em sua zona rural (ARAÚJO, 2018). Este atributo ainda está associado aos deslocamentos de trabalhadores, visto que a produção do setor sucroenergético registrou uma demanda de mão de obra mais ampla comparado a outras culturas como: soja, café e arroz, entre outras (MATOS; FRATARI; CARVALHO, 2018).

Partindo da divisão espacial do trabalho podemos explicar a migração dos cortadores de cana, visto que as regiões de origem e destino estão enquadradas perfeitamente em escala nacional, assim é possível explicar as causas e consequências do fluxo migratório a partir do referencial teórico proposto. De acordo com Singer (1998), as desigualdades regionais constituem a razão das migrações. A modalidade espacial se expressa nas relações entre demanda por trabalhadores e a oferta de mão de obra, associadas às articulações entre processos econômicos, políticos e sociais ocorridos em distintas escalas.

Este artigo não trata de um processo novo de deslocamento, haja vista que a migração de nordestinos para Ituiutaba antecede a expansão da cultura da cana-de-açúcar no município, entretanto podemos reiterar o acréscimo de novos elementos e contornos resultante dos atributos recentes da economia e da sociedade brasileira. Simultaneamente, 
a extinção dos postos de trabalho a partir da utilização de maquinário no corte da cana que se coloca como um novo desafio.

Todo esse processo de desenvolvimento foi explícito na cidade de Itiutaba, a instalação de agroindústrias na região possibilitando um fluxo migratório oriundo da região Nordeste do Brasil, com isso a chegada dos migrantes nordestinos para o município de Ituiutaba foi em larga escala. Assim, os homens chegavam para o trabalho no corte manual da cana-de- açúcar e depois de estabelecidos na cidade, traziam o restante da sua família, suas esposas, mães, irmãs e os filhos mais novos.

Objetiva-se, portanto, neste artigo, compreender a realidade dos migrantes nordestinos no município de Ituiutaba, Minas Gerais, pois desde a década de 1990 foram evidentes as modificações que aconteceram tanto no meio urbano quanto no meio rural do município, alterações essas caracterizadas por uma nova dinâmica econômica que teve sua abertura com o procedimento de reestruturação produtiva anteriormente baseada na produção de arroz, da bovinocultura, da suinocultura e da agricultura familiar pela produção de cana-de-açúcar para produção de açúcar, álcool e derivados (SILVA, 1997).

No presente artigo, a análise se volta para a abordagem das trajetórias migratórias dos canavieiros. Nesse contexto, as narrativas deles foram fundamentais ao permitir reconstituir motivações, causas e desdobramentos. A partir da coleta de histórias de vida se entende como os relatos orais são essenciais para a compreensão desta modalidade migratória. Parte-se primeiro, portanto, das considerações referentes às opções metodológicas deste trabalho e sua aplicação nas dimensões da mobilidade espacial dos canavieiros. Ao obter a teoria migratória como aporte teórico é possível construir um diálogo com esta e outras pesquisas sobre a temática no país. Assim, este artigo aborda os significados desta análise sobre os trabalhadores canavieiros em relação à produção acadêmica sobre a migração, mas essencialmente no contexto social, político e econômico do Brasil.

Os trabalhos de Durham (1984) e Singer (1998) constituem as análises essenciais do processo de êxodo rural, na dinâmica migratória no território brasileiro no século XX. Neste artigo utilizamos as análises destes autores, mas como novos elementos relacionados aos recortes espaciais e temporais, diante da crise do setor da agroindústria na região. Lamentavelmente esses trabalhadores mantêm falsas esperanças de que recebendo mais terão melhores condições de vida, ainda que para isso necessitem cortar mais de 12 toneladas de cana ao dia. Contudo, desde o ano de 2014, não existe o corte da cana de açúcar na região de Ituiutaba, já que indústrias como as do Grupo João Lyra assumiram falência e interromperam suas atividades, e outras como a BP (British Petroleum) concordaram com o corte da cana 100\% mecanizado a fim de ampliar a produção.

As entrevistas foram realizadas a partir de um roteiro semiestruturado com questões que norteavam as narrativas dos trabalhadores migrantes a respeito de suas experiências. 
Assim, a partir das questões baseadas em referências teóricas de pesquisas sobre migrações foi constituído um roteiro para as entrevistas com os trabalhadores migrantes considerando os seguintes fatores da mobilidade espacial: atributos e características da origem, as motivações para o engajamento no movimento, rede e contatos, e intenções e perspectivas para o futuro.

\section{MIGRAÇÃO DOS CORTADORES DE CANA PARA MICRORREGIÃO DE ITUIUTABA}

Os elementos que dão origem à compreensão das migrações são fundamentas para o entendimento desta dinâmica. Partindo de Singer (1998), destaca-se que as migrações internas são decorrentes das causas e determinantes estruturais que condicionam 0 comportamento dos sujeitos, ou seja, tanto dos aspectos históricos e institucionais como modificações estruturais econômicas. Deste modo, o autor estabelece uma relação entre migrações e industrialização. Portanto, as condições materiais das áreas de origem implicam em dificuldades para o desenvolvimento de recursos domiciliares ou de grupos para garantir sua sobrevivência.

O autor, no livro intitulado Migrações internas: considerações teóricas sobre o seu estudo (1998), aborda como as migrações internas são tantos resultados dos aspectos históricos e institucionais como de alterações estruturais e espaciais da economia. Deste modo, devem ser analisadas a partir da perspectiva do processo global, e caracterizadas como uma dinâmica social, sendo que a unidade atuante é o grupo ou classe social. O autor estabelece relações entre migrações e industrialização. Também articula algumas hipóteses ao longo do texto. No primeiro momento, formula a hipótese da existência de tipos historicamente definidos de migrações, condicionados pela industrialização. $O$ autor afirma que a industrialização altera as técnicas de produção e a divisão social do trabalho. A concentração de capital leva à concorrência espacial das atividades e à urbanização, porém as características históricas e institucionais devem ser consideradas no processo de migrações.

O processo de industrialização é influenciado por arranjos institucionais e agem na dimensão econômica. Singer (1998) aponta que as desigualdades regionais são o "motor" das migrações internas relacionadas à industrialização. $O$ autor assinala dois fatores de expulsão causadores das migrações: a mudança e a estagnação. Os elementos de mudança estão relacionados ao processo de industrialização e promove uma migração ampla, diferente das características de estagnação, mas os dois se reportam às áreas rurais e ao fluxo de pessoas. O papel do Estado pode ser utilizado para levar o desenvolvimento regional em áreas estagnadas, desequilibradas, criada pelo próprio processo de industrialização, como também para reforçar o desenvolvimento regional. 
Singer (1998) ainda analisa os fatores de atração norteadores dos fluxos migratórios, sendo a demanda por força de trabalho o mais relevante. O autor propõe três hipóteses sobre os migrantes não serem absorvidos pelo mercado de trabalho no local de origem: desequilíbrio regional, desqualificação entre oferta e demanda, e inferioridade econômica. $A$ procura de força de trabalho nas cidades é uma função do tamanho e da composição do produto gerado pela economia urbana.

Estes deslocamentos estão ligados às desigualdades regionais que evidenciam o papel da divisão do trabalho em múltiplas escalas espaciais, deste modo é importante também fazer uma reflexão mais extensa a respeito dos motivos e consequências dos movimentos populacionais.

De acordo com Singer (1998) as migrações estão associadas às desigualdades regionais, o motor das migrações. As condições materiais de difícil ampliação de recursos, concentração da propriedade fundiária e inserção problemática em divisões do trabalho, envolvem um conjunto de municípios em regiões aonde a pobreza e a falta de oportunidades caracterizam os polos emissores de migrações. Autores como Pessôa (1988) e Cleps Júnior (2009) destacam esse caráter regional das áreas de origem dos cortadores de cana no Triangulo Mineiro, em grande parte oriunda da região Nordeste do Brasil.

Partindo de outra perspectiva teórico-metodológica, Eunice Durham, no livro $A$ caminho da cidade: $A$ vida rural e a migração para São Paulo (1984), analisa as dimensões individuais, familiares e comunitárias da migração, ou seja, os fatores que constituem as motivações dos sujeitos engajados no processo migratório. Embora Singer e Durham ofereçam interpretações bastante relevantes para análise da mobilidade dos cortadores de cana, os dois autores examinam a migração a partir do movimento rural-urbano, sendo assim não permitem uma interpretação direta de mobilidade com temporalidades e espacialidades diferentes, como é o caso do estudo de caso do presente artigo. As discussões teóricas sobre as migrações internas no território brasileiro na abordagem do movimento rural-urbano são extremamente relevantes, mas é preciso determinar um campo específico de questões conceituais para interpretação da migração dos trabalhadores canavieiros, uma vez que seu fluxo migratório é caracterizado pela extinção dos postos de trabalho ocupados por esses trabalhadores canavieiros, o que se coloca como um desafio, ocasionando novas tipologias de migração: rural-urbano, urbano-urbano, inter e intrarregional.

No entanto, em relação aos destinos, não necessariamente os migrantes oriundos do campo se deslocam para grandes áreas urbanas, as metrópoles. Os mesmos podem ser atraídos para áreas rurais e cidades médias e pequenas do interior brasileiro, dado o caráter regional desse tipo de migração, que se concretiza por meio da territorialização do setor sucroenergético e de sua constituição histórica. Silva e Santos (2014), e Fonseca e Santos, 
(2011) entre outros, tratam do aspecto do complexo setor canavieiro e na microrregião de Ituiutaba, Minas Gerais (MATOS; FRATARI; CARVALHO, 2018).

Partimos da pressuposição em que o trabalho de campo é indispensável na análise sócio espacial das relações sociedade-espaço. A metodologia de investigação desenvolvida aqui contou com uma convivência com os migrantes permanecidos em Ituiutaba por cinco meses (de janeiro a maio de 2017), com a realização de vinte e cinco entrevistas através do trabalho de campo e outras inúmeras conversas informais aliadas às observações na produção do espaço em Ituiutaba. Relações de profunda desigualdade colocavam-se aí e só a partir deste "acompanhamento" cotidiano das interações dos migrantes com o município que pudemos ter mais clareza dessas sobreposições de poder. Na figura 2 pode ser analisada a localização do bairro Novo Tempo II, em Ituiutaba, MG.

Figura 2 - Localização do Bairro Novo Tempo II

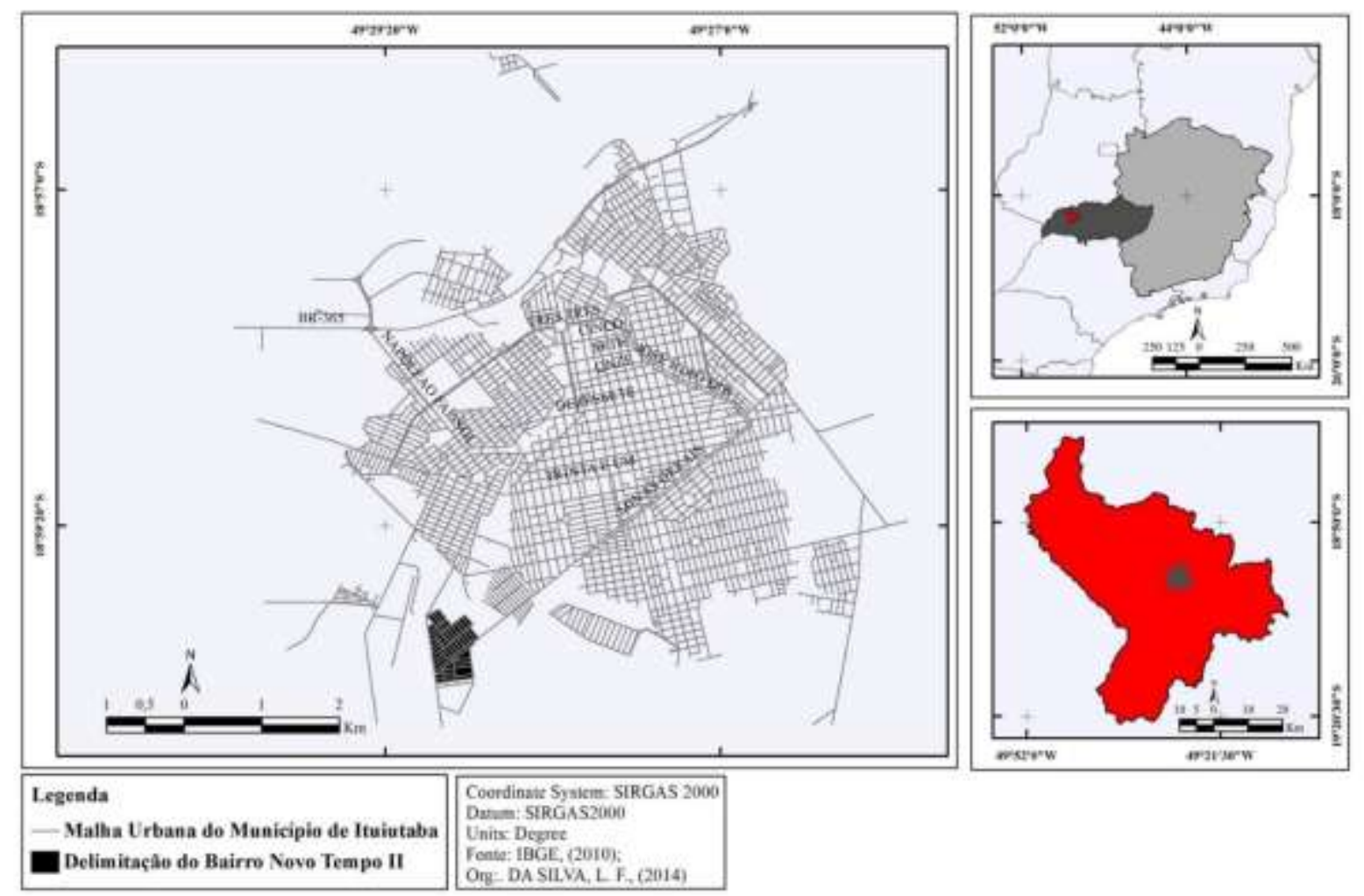

Fonte: IBGE (2014), organizado por D. F.C. Araújo e L. F. Silva, 2017.

Neste sentido buscarmos sempre, através da pontuação e das palavras a melhor e mais fiel passagem da oralidade para a escrita, num processo de valorização da informação e dos sujeitos entrevistados. As fontes orais foram consideradas em nossa investigação enquanto informação qualitativa. As falas obtidas diretamente com os sujeitos envolvidos no processo (os migrantes) permitiram, aliás, dar luz sobre as condições de trabalho na cana, os interstícios das relações de poder, as representações, a memória, a identidade, o conflito 
e da alteridade, as negociações, os contatos tecidos na trajetória migratória, e os conflitos e a solidariedade entre parentes e amigos, que ajudaram (ou não) na constituição de vínculos sociais, através da ressignificação cultural e política no novo território. As fontes orais nos ajudaram a questionar o status de verdade através das redes de poderes e de dizeres de determinada produção territorial de uma identidade hegemônica, na qual se circunscreve Ituiutaba.

\section{Paulo de Araújo}

Paulo de Araújo nasceu em São Miguel dos Campos, Alagoas e migrou para Ituiutaba em 2001 com sua mulher e seus três filhos, e é morador do bairro Novo Tempo II há mais de dez anos. Ele disse que não era mais possível ficar em Alagoas, e com a possibilidade de se mudar para Ituiutaba, decidiu vir para o Triângulo Mineiro a convite dos irmãos migrantes que estão na região desde 1999 para o corte de cana. Hoje, aos 40 anos, com uma "fala mansa", comenta, ao tomar seu café, como foi esse processo de migração, e o incentivo e o apoio dos irmãos para a bem-sucedida inserção na atividade da lavoura de cana:

Eu nasci no município de São Miguel dos Campos, Alagoas [...] Eu vim em 2001. Eu vim com três filhas e uma nasceu aqui. Tenho quatro [filhas] mulher [...] Ah! Porque lá, no tempo ainda dava pra viver, mas, depois teve um meu irmão que foi lá e me convidou pra vir pra cá, aí né? Tinha dois irmão, já aqui [em Ituiutaba]. Eles vieram, em 1999, já tavam aí. É que lá não tinha resultado nenhum, né? Nós morava na fazenda, tudo a boi, não tinha trator. Daí vim aqui pra fazer futuro [...] O que cabia no caminhão, as coisinha, né? [...] Eu vendi, eu tinha cinco alqueire de terra lá, eu vendi lá e comprei uma casa aqui com o dinheiro, né? Aqui tinha mais futuro, né? Porque lá na fazenda tava morto, né? [...] Eu morei sete meses na casa do meu irmão quando cheguei aqui na cidade, até construir aqui no bairro. Desde que cheguei eu fui mexer com lavoura de cana. Já tinha os irmão que trabalhava no corte de cana e eu também fui mexê, né? (Paulo de Araújo).

Os irmãos vieram para trabalhar em Ituiutaba, por isso Paulo foi incentivado a migrar. As dificuldades em Alagoas e a falta de resultados na agricultura o motivou a sair da sua terra de origem e, com o apoio dos irmãos, conseguiu se inserir socialmente por meio do trabalho na lavoura na nova cidade.

Em seus estudos sobre as migrações do campo para a cidade, Durham (1984) avalia que tais deslocamentos não decorrem, em geral, de uma situação anormal de fome ou miséria, ao contrário, a migração aparece como uma resposta às condições normais de existência. "O trabalhador abandona a zona rural quando percebe que 'não pode melhorar de vida', isto é, a sua miséria é uma condição permanente. Isto não quer dizer que calamidades naturais ou acidentes não sejam fatores que precipitem a emigração" 
(DURHAM, 1984, p. 170). Ou seja, na avaliação da autora, na maioria das vezes a migração é impulsionada por uma situação desfavorável vista como permanente pelos próprios trabalhadores. Nas suas palavras:

Os migrantes explicam sempre a migração como uma tentativa de "melhorar de vida" [...] Limitam-se em geral a dizer que migraram porque "a vida lá era difícil", "não tinha emprego", "pagavam pouco" [...] a emigração é provocada por tensões que se manifestam no campo econômico e se traduzem em salários baixos, rendimento insuficiente da produção agrícola e falta de emprego remunerado como alternativa [...]. O trabalhador abandona a zona rural ou os pequenos centros urbanos quando percebe que "não pode melhorar de vida", isto é, que sua miséria é uma condição permanente [...]. A esses aspectos negativos se opõe a expectativa positiva das possibilidades que a vida urbana na agricultura "do sul" poderão propiciar (DURHAM, 1984, p. 188).

Verifica-se que com o processo de "modernização da agricultura" no campo brasileiro, aqueles trabalhadores rurais que não tinham possibilidades de comprar maquinários e nem incentivos do Estado para se manter no campo começaram a "desanimar" e a desejar o deslocamento, sendo a mobilidade uma fuga de um território onde as expectativas estavam frustradas, o que mobilizava esperanças de melhoria em outro território, onde as possibilidades de horizontes sociais pareciam muitas, e onde os irmãos the ofereciam segurança através do trabalho e das relações intrafamiliares. Como menciona Paulo: "É que lá não tinha resultado nenhum, né? Nós morava na fazenda, tudo a boi, não tinha trator. Daí vim aqui pra fazer futuro". A necessidade e/ou desejo de "fazer um futuro melhor" em outro lugar condicionaram a mobilidade, aliado ao processo seletivo ocorrido no campo pelo advento da "modernização da agricultura", que agravava ainda mais as condições desiguais do campo, fazendo com que aqueles que não puderam se modernizar não vislumbrassem alternativas a não ser a mudança. Isso aparece na trajetória migratória de Paulo: a migração Ihe apareceu como único horizonte possível, a mudança de lugar e de relações sociais (o que nem sempre ocorreu) mobilizava o engajamento na melhoria das condições de vida.

As compreensões teóricas apontadas por Arendt (2007, p. 244) com relação ao processo de enraizamento nos auxiliam a esclarecer as questões sobre a migração determinada pela modernização do capitalismo. Assim, para essa autora, não ter raízes "[...] significa não ter no mundo um lugar reconhecido e garantido pelos outros; ser supérfluo, não pertencer ao mundo de forma alguma". (ARENDT, 2007, p. 244).

Em diálogo com Hannah Arendt, Simone Weil (1996) aponta para a hipótese de que a concentração de terras, a modernização e o desenvolvimento do campo brasileiro passaram a representar, para milhares de trabalhadores expulsos do campo, uma história de constantes deslocamentos, em função das dificuldades de enraizamento, principalmente se essa tentativa for feita na cidade. Assim, o desenraizamento traz ao homem, em sentido 
genérico, sentimentos marcados por saudades de pessoas e de lugares. Quem é desenraizado vivencia múltiplas experiências, que acabam, por vezes, suprimindo sua própria identidade. Daí que para (WEIL, 1996 p. 347):

O enraizamento é talvez a necessidade mais importante e mais desconhecida da alma humana. É uma das mais difíceis de definir. O ser humano tem uma raiz por sua participação real, ativa e natural na existência de uma coletividade que conserva vivos certos tesouros do passado e certos pressentimentos do futuro. Participação natural, isto é, que vem automaticamente do lugar, do nascimento, da profissão, do ambiente.

A esse respeito Bosi (1992, p. 17), no artigo "Cultura e desenraizamento ...", ao analisar os impactos provocados pela migração compulsória na vida do camponês, afirma:

O migrante perde sua paisagem natal, a roça, as águas, as matas, a caça, a lenha, os animais, a casa, os vizinhos, as festas, a sua maneira de se vestir, o entoado nativo de falar, de viver, de louvar a seu Deus. Suas múltiplas raízes se partem. Na cidade, a sua fala é chamada 'código restrito' pelos linguistas; seu jeito de viver, 'carência cultural', sua religião, crendice ou folclore. Seria mais justo pensar a cultura de um povo migrante em termos de desenraizamento. Não buscar o que se perdeu: as raízes já foram arrancadas, mas procurar o que pode renascer nessa terra de erosão.

Se tudo isso são aspectos negativos na vida desses migrantes, eles devem ser relativizados pelos aspectos positivos que a cidade oferece, visto que a cidade pode representar a esperança de melhores condições de acesso ao atendimento das necessidades de saúde, educação, saneamento, lazer e novos hábitos consumistas.

Foi nesta perspectiva de sair da pobreza no interior de alagoas que Paulo encontrou uma possibilidade de melhorar de vida na cidade. Com ajuda de seus dois irmãos ele conseguiu viabilizar sua vinda para Ituiutaba através das redes de parentesco.

\section{Dona Antônia}

$\mathrm{Na}$ busca pelo contato com os migrantes que hoje residem no bairro Novo Tempo II encontramos Dona Antônia, alagoana, que chegou a Ituiutaba no ano de 1985 para colheita de algodão. Embora sua inserção no novo território tenha sido anterior ao período da expansão da indústria da cana na região, sua narrativa é interessante para percebemos às motivações do fluxo migratório para Ituiutaba na década de 1980. Recebeu-nos com muita boa vontade para a entrevista. Chegamos à sua casa no horário do entardecer, ela assistia a missa pela TV, sua casa estava repleta de símbolos religiosos, o catolicismo marcava as paredes da moradia com imagens de santos e fotografias da família. Começamos a trocar 
as primeiras palavras e, ela, muita disposta, nos narrou como foi sua chegada naquele tempo em 1985:

\begin{abstract}
Viemos de São Miguel dos Campos, Alagoas, em 1985, apesar de que um ano e pouco a gente ficou em Capinópolis, aqui do lado; nós chegamos lá e ficamos na casa de um cunhado, e depois que meu marido perdeu o emprego, viemos aqui pra Ituiutaba, aqui é melhor, né? Não pudemos ficar sem trabalho, lá não conseguimos emprego, viemos aqui pra Ituiutaba, aqui era mais fácil encontra trabalho, né? Ele [o marido] se mandô pra cá e daí viemos [...] Meu marido veio duas vezes antes pra ver como é aí já veio mais gente ver junto lá de São Miguel dos Campos... Meu marido conseguiu emprego em Ituiutaba, ele se encontrou com um conhecido daqui que morava em Capinópolis, ele era o chefe de quem trabalhava na usina, né... Aí meu marido conseguiu arrumar emprego. Daí, quando chegaram a Ituiutaba, era o lote ainda aqui no bairro, né? No começo eu não gostava daqui não, viu... [...] não tinha nada e era muito afastado da cidade, né! Aí com o tempo fui me acostumado (Dona Antônia).
\end{abstract}

O depoimento da migrante é importante a fim de compreender a conjuntura ocorrida pela mobilidade nesse período (ciclo econômico do algodão); constatamos que a migração se realizava em fases, pois de Capinópolis se deslocavam para Ituiutaba. A procura de trabalho demonstra um forte fator motivacional, como afirma Antônia, "[...] não pudemos ficar sem trabalho, lá não conseguimos emprego, viemos aqui pra Ituiutaba, aqui era mais fácil encontra trabalho, né?" Através das redes de amizade, o marido de Antônia migrou para Ituiutaba; no caminho, encontrou um conhecido, e por ser do Rio Grande do Norte teve a confiança de buscar informação sobre local para morar, e permitiu que ele ficasse sabendo sobre a existência do Bairro Novo Tempo II; era segundo o contato feito, "[...] uma oportunidade de trabalho e para morar". A informação viabilizada por meio das redes de amizade foi imprescindível para o processo migratório e para que o migrante encontrasse oportunidades de inserção social e territorial. Ao encontro com esse relato podemos observar Peixoto (2004, p. 29) dialogar intimamente com teorias das redes sociais e do capital social:

[...] os migrantes não atuam isoladamente, nem no ato de reflexão inicial, nem na realização dos percursos concretos, nem nas formas de integração no destino. Eles estão inseridos em redes de conterrâneos, familiares ou, inclusivamente, agentes promotores da imigração, que fornecem a informação, as escolhas disponíveis, os apoios e a fixação definitiva.

Podemos apreender a experiência cotidiana dos que saem de um lugar para o outro; a variabilidade de suas práticas sociais; como as estratégias e os recursos são disponibilizados a partir dos contatos tecidos no caminho da migração; as relações de sociabilidade entre os migrantes e as conjunturas internas ao seu grupo de familiares; relações que se apresentam, na maioria das vezes, ausentes das análises macroestruturais. 


\section{Lucia da Silva}

Lucia da Silva, que veio de União dos Palmares, Alagoas para acompanhar o marido na construção de um galpão na Usina Vale do Paranaíba, instalada no município de Capinópolis (MG), nos relatou sua migração para Minas Gerais, e as cidades onde morou parte da sua vida e onde teve seus filhos. Apontou, também, as condições precárias das vias de acesso a Minas Gerais e o tempo da mudança:

Eu nasci em Alagoas, União dos Palmares era a cidade. Nós viemo antes pra Capinópolis antes de vir pra cá. Nós saímo de Alagoas pra Capinópolis, foi em 1990. Moremo dois anos em Capinópolis [...] Aí, depois a gente veio morá em Santa Vitória, mas daí ali só moremo seis meses. Daí viemo pra cá [ltuiutaba] em 1992 [...] a mudança veio só a nossa no caminhão. Naquele tempo, levamos três dias inteiro pra vir de União dos Palmares até aqui. Estrada de chão tinha só barro, atoleiro (risos) (Lucia da Silva).

Lucia ainda assinalou que o motivo da vinda a Minas Gerais esteve relacionado à mobilidade da força de trabalho do seu marido, deslocado para trabalhar em uma indústria que se instalou em Capinópolis:

O meu marido trabalhava numa usina de cana em Alagoas, e essa firma vinha construí uma usina em Capinópolis. Aí ele teve que vir ajudar a construir o barracão aqui, a instalação. Só que meu marido perdeu o emprego. Aí acabou a comida, acabou o dinheirinho que nós tínhamos. Sem comida, sem dinheiro, passando fome, se não fosse os vizinho ajudá [...]. Daí ele arrumô serviço aqui numa fazenda e nos mudamo pra Ituiutaba. Daqueles que vieram juntos pra construir a usina, eram só três com o meu marido que trabalhavam com ele. Mas os outros dois eram homem que vieram sozinho, né? Sem família, aí voltaram. [...]. Daí ele foi trabalhá na fazenda pra poder ter dinheiro, e teve que pedir dinheiro adiantado, pra poder ir no mercado ir comprá comida, pra poder comer e ir trabalhar, foi assim naquela época. Naquela época, mas ele [o dono da fazenda] cedeu naquela época dinheiro, porque era tudo estranho, os mercado não iam ceder fiado, a gente não era conhecido e não tinha dinheiro pra comprar. Como é que cê ia compra pra comer? (Lucia).

Na fala de Lucia, é possível observar, através da decisão de ficar em Ituiutaba, mesmo em condições adversas e precárias (sem emprego e dinheiro), quando seu marido "estava desesperado" e queria voltar para Alagoas para junto de seus familiares, o papel da mulher na migração, o papel de definir, no âmbito familiar, em uma parcela do espaço, como ela mesma nos disse:

Voltar! lii... o meu marido queria voltar de tudo jeito daqui. Eu disse pra ele: "Não! Vamo firma o pé aqui. Já que viemo é aqui que vamo fica!" (risos). Ele queria voltar por desespero, né? Logo depois que ele viu que não tava dando certo, né? Eu disse: "Não senhor. Se Deus quiser a gente vai 
endireitar. Não é voltando pra trás que a gente vai pra frente, é indo pra frente que tem que ir". Daí foi indo, no começo a gente sofreu bastante, né? Mas pelo menos o que comer e onde morar a gente passou a ter depois (Lucia).

As condições adversas encontradas por Lúcia e seu marido no novo território, através da falta de trabalho, potencializou, pelo sentimento de desespero, o desejo de voltar. A possibilidade de voltar para onde se é conhecido, para onde se tem abrigo, amigos e familiares, combinada com a instabilidade e/ou a insegurança no novo território, desencadeou o desejo de voltar, o querer voltar. O enraizamento do migrante no novo território condiciona a forma como as novas experiências serão avaliadas como positivas ou negativas. Sobre as experiências negativas, Ribeiro (2000, p. 65) afirma:

\begin{abstract}
A expulsão dos moradores do campo significa para muitos o sentimento de perda de parte de sua identidade expressa no valor simbólico e mítico que a terra para eles representa. No instante em que se deparam com uma situação de "desgarrados" da terra, o modo de vida rural aparece em suas memórias tão somente como recordações, lembranças. No entanto, esse rememorar os leva à descoberta e à tomada de consciência a respeito de uma realidade de exploração e de exclusão social vivida na cidade.
\end{abstract}

Entretanto, mesmo sendo negativo, como no caso de Lúcia, o migrante pode ficar na cidade de destino. O voltar, por isso, está ligado também ao sentimento de fracasso, de não ter conseguido se dar bem, pois a migração carrega as esperanças de novas e boas oportunidades. No entanto, esta foi esmorecida, no caso de Lúcia, com a falta de emprego e de condições financeiras favoráveis para sobrevivência sua e de seu marido. Ainda assim, isso não impediu que os mesmos continuassem e se enraizassem (mesmo que no primeiro momento precariamente) no território. O enraizamento, nesse caso, se efetivou com uma decisão pessoal que insistiu na permanência no território, mesmo em condições precárias e adversas.

Por outro lado, formam-se redes de solidariedade entre os migrantes, redes essas que permitem não só a comunicação e a troca de informações entre eles, mas também o auxílio mútuo. No seu estudo sobre os camponeses trabalhadores migrantes, Menezes (1985, p. 109) analisou as várias formas de redes estabelecidas entre os mesmos. Para a autora:

O grupo analisado está envolvido não apenas com migração sazonal para a plantation canavieira, mas também com migrações de longa distância e duração, em geral para cidades no Sudeste do Brasil. Aqueles que se deslocam mantêm-se em contato com a família, através de uma variedade de formas de comunicação. Uma destas é a circulação de pessoas, através das quais se enviam dinheiro ou outras mercadorias. Os que migram pela primeira vez são acompanhados por amigos ou parentes e aqueles que retornam gastam a maior parte do tempo visitando colegas e familiares. Todas essas interações sociais atuam como canais difusos para a comunicação das experiências dos migrantes. (MENEZES, 1985, p. 109). 
Assim, com ajuda dos amigos foi possível a permanência da família de Lúcia em Ituiutaba. Os amigos que trabalhavam com o marido de Lúcia auxiliaram ao indicar um emprego na Usina Triálcool. Lúcia nos relata com alegria como o marido conseguiu arrumar um novo emprego.

A gente estava com muitas dividas no mercado, devendo aluguel, eu já estava desanimada com tudo que estava acontecendo com a gente aqui. Aí a Usina Triálcool começou a contratar o pessoal para cortar cana. Meu marido foi avisado pelo amigo nosso que já trabalhava lá. Nossa, quando ele (marido) chegou em casa com o material de trabalho fiquei muito feliz (Lúcia).

A possibilidade de permanência através do emprego na usina foi determinante para a família de Lucia permanecer em Ituiutaba. Ela cumpriu, como outras tantas mulheres, o papel social de mães dispostas a enfrentar todas as dificuldades no processo de migração.

\section{Ana Lucia}

Ana Lucia nasceu em Campo Alegre, município de Alagoas, e no ano de 2004 veio para Ituiutaba com seu marido para trabalhar na colheita da cana-de-açúcar. Trabalhou desde criança na roça e em casa. Depois de casada, passou a trabalhar na terra do marido. Ela nos recebeu em sua casa com a mesa repleta de quitanda (frutas) e café. Ela nos informou, em conversa amistosa, os motivos de sua mobilidade:

Lá de Alagoas eu vim casada. Casei lá em Alagoas daí vim morar pra cá. No ano de 2004, que chegamo em Ituiutaba [...] Eu vim de Campo Alegre. Lá nós trabalhava tudo na roça, depois que nós viemos pra cá eu fui trabalhá de diarista e o meu marido começou a trabalhar na usina. Meus pais vieram uns quatro anos antes que nós viemos pra cá, os pais, daí tinha um tio meu aqui já antes. Esse tio fez umas quatros viagens pra Alagoas contando às maravilhas que tinha pra cá, dizendo que aqui era um lugar bom, novo, que tinha oportunidade. Aí nós também era muito ligado aos meus pais e, sabe? Nós acabemo ficando meio sozinho em Campo Alegre e viemo pra Minas Gerais. Aqui os meus pais ajudaram nós no começo a se ajeitá na vida, arrumá serviço e daí a família ficou mais próxima, mas unida, né? Aí ficou melhor pra se viver também (Ana Lucia).

Um ponto fundamental na rede de relações sociais é a ajuda familiar e a relação afetiva, de solidariedade entre os parentes, o que não implica na inexistência de conflitos e tensões que também permeiam estas relações. Nesta trajetória migratória verifica-se o papel desempenhado pela informação levada através de um familiar (tio) que tece contatos e apresenta o território de destino, no caso a cidade de Ituiutaba, como um lugar "maravilhoso". 
Em razão da experiência de solidão, sem a presença de seus familiares, sem a possibilidade de atualização dos vínculos afetivos e sem a regularidade da manutenção dos laços fortes com os pais, o município de origem se transforma em uma espécie de "não lugar". O que motiva Ana Lucia e seu marido a migrar para Minas Gerais, próxima de seus familiares em Ituiutaba, pois, como afirma a migrante: "Nós acabemo ficando meio sozinho em Alagoas e viemo pra Minas Gerais". Os vínculos familiares (fortes) podem definir o território de destino do migrante. Sendo o território uma relação social em um determinado recorte espacial, a ausência dos familiares (os pais) em Alagoas fez com que Ana Lucia se sentisse sozinha e sem apoio do núcleo familiar em Campo Alegre. Logo, o horizonte de reaproximação, isto é, o enraizamento das relações sociais em Minas Gerais, no município de Ituiutaba, se processou com a ajuda dos familiares: "Aqui os meus pais nos ajudaram no começo a se ajeita na vida, arruma serviço e daí a família ficou mais próxima, mas unida, né? Aí ficou melhor pra se viver também". Essa ajuda acarretou, portanto, uma forma de se enraizar, através do trabalho bem como da relação afetiva com o território de destino, potencializada pelo convívio familiar, as visitas recíprocas, a colaboração mútua, a amizade com os parentes.

As motivações que perpassaram a migração para o Triangulo Mineiro contaram com a presença efetiva das redes de relações sociais, na construção e manutenção de uma rede, sendo que a troca de informações e as relações de amizade e de parentesco propiciaram um forte vínculo territorial para a mobilidade de alagoanos, cearenses, baianos, pernambucanos e piauienses para o território mineiro. As motivações para o deslocamento se deram - como demonstramos através das trajetórias migratórias - em função de motivações vinculadas aos interesses econômicos, mas também por meio de relações de amizade e de parentesco. Enfim, para além dos elementos objetivos como a busca de trabalho, elementos subjetivos como o desejo, a amizade e/ou a afetividade familiar, dentre outros, desempenharam papel fundamental.

\section{Maria Tereza}

Maria Teresa, em uma narrativa cheia de emoção, descreveu sua vinda para Minas Gerais, relembrando o Rio Grande do Norte como território da nostalgia e do pertencimento, ligado aos familiares, o que motivava seu desejo de voltar:

Era bastante diferente aqui [Ituiutaba] do Rio Grande do Norte. A gente era diferente, o lugar, né? Não era quem nem lá. Lá tinha fruta, tinha de tudo, mas depois a gente se acostumou. Aqui era só mato quando chegando no bairro. Tenha poucas casinhas aqui, né! Mas, mais era a saudade que a gente tinha de lá, né? Tinha saudade da gente de lá e do lugar. Porque a gente nasceu e se criou lá, né? A gente veio pra cá chorando, parecia que a 
gente ia no fim do mundo! Sabe? Que não voltava mais, a gente pensava isso [...] Mas a gente sente, ainda agora eu sinto saudade de lá. Eu se fosse pra dizer, sair daqui, eu queria morar pro Rio Grande Norte de novo. Porque a gente lá no irmão a gente se sente à vontade, porque Deus o livre! Não é fácil! [...] A gente queria experimentar mudar a vida, fazer mais progresso, né? Lá as terra era fraca, magrinha, dava pouco já, não tinha adubo, agora é tudo máquina, adubo e a gente plantava só com a enxadinha, e as terra meio magrinha não dava nada, não dava mais, achava que era melhor, fazer futuro aqui [...] Ele [o marido] já tinha vindo antes, arrumado o lugar pra gente e emprego. Mas parecia que a gente vinha no fim do mundo. $A$ gente sentiu muita saudade de lá (Maria Teresa).

As relações identitárias, vinculadas à cultura de amizade intrafamiliar no interior do Rio Grande do Norte, enraizavam e davam sustentação à migrante através dos vínculos afetivos que condicionaram com a mobilidade o sentimento da saudade, do território da saudade, da saudade dos familiares e das relações tecidas no interior de um território cultural: "Mas a gente sente, ainda agora eu sinto saudade de lá. Eu se fosse pra dizer, sair daqui, eu queria morar pro Rio Grande do Norte de novo. Porque a gente lá no irmão a gente se sente à vontade"; ou seja, a migração condiciona a saudade e o desejo do retorno.

A vontade de experimentar mudar de vida está atrelada à migração, na procura por melhores condições de vida, base material e social. Mas após sair do seu lugar de origem, o sujeito sente saudades de onde saiu e de onde tecia suas relações, especialmente as afetivas: aquelas ligadas aos amigos e aos familiares. Assim, a migração se manifestou na fala da migrante como algo contraditório e ambíguo:

Se eu fosse mora pra lá, eu sentia saudade daqui agora, porque a gente agora, o nosso lugar é aqui agora, porque a gente se sente bem aqui. Eu acho que digo que ia morar pra lá, mas a gente não ia mais porque a gente se acostumou aqui agora, tem os filhos... a gente tem muito amigo, conhecido, conhece a cidade inteira, né? (Maria Teresa).

O sonho de Maria Teresa é o de um dia poder reconstruir aquilo que D’Aquino (1998, p. 18) chama de "velho estilo de vida".

[...] o lar, a lareira, o local de reunião da família, o ambiente em que a família se reproduz, através da reprodução do corpo e das práticas grupais. A casa, nesse sentido, não é apenas um espaço de organização social. É também espaço de projeção do corpo, um espaço pessoal, um espaço em construção, em que as lembranças de outras moradas estão presentes, articulando as práticas individuais e grupais.

A migração possibilita compreender ou problematizar aspectos contraditórios da experiência da divisão em dois lugares: o de origem e o de destino. A saudade de sua terra, o lugar de origem deixado por Teresa não foram lembranças perdidas ou esquecidas, estão na sua memória, nas paisagens e nas relações identitárias que a ligam ao que foi deixado 
no Rio Grande do Norte. No território de destino da migração, com o passar do tempo, novas relações foram sendo tecidas, ajudando na permanência da vida de Maria Teresa. Estas quatro trajetórias trouxeram à tona o rosto feminino da migração do Norte e Nordeste para as usinas da microrregião de Ituiutaba no final da década de 1990 até 2000.

\section{CONSIDERAÇÕES FINAIS}

Almejamos neste artigo contribuir aos estudos das migrações para Ituiutaba, Minas Gerais a partir das trajetórias de migrantes com destino ao município. O artigo é baseado majoritariamente nas narrativas dos migrantes e suas trajetórias dos estados de Alagoas e Rio Grande do Norte, a partir do final da década de 1980, que partiram com suas famílias para o corte da cana ou lavouras de algodão durante muitos anos. As trajetórias destas mulheres e homens mostraram que as migrações não são meramente deslocamentos demográficos num determinado espaço social. Ao mesmo tempo em que uns partem, outros ficam, e os chamados pontos de origem e de destino são constituídos por redes. Nesse sentido, analisamos aqui, a partir de trajetórias individuais de mobilidade, o papel das redes de relações sociais reticulares para a construção de uma rede, aliado à condição migratória entre o território de origem e destino na migração.

Assim, a pesquisa possui grande importância acadêmica e social, já que demonstra a situação do migrante nordestino através de dados obtidos por entrevistas semiestruturadas de forma que a realidade seja dita pelos migrantes nordestinos, evitando, assim, a distorção dos fatos e uma oportunidade de dar voz a estes sujeitos.

Faz-se necessário o entendimento das condições de vida e dos processos relacionados às migrações, uma vez que essa população migrante, muitas vezes negligenciada pelo poder público e pela população local, auxilia na movimentação da economia do município, em seu crescimento e na constituição de sua cultura. O século XXI apresenta tendência de continuidade das migrações, sejam elas nas escalas regionais ou nacionais e internacionais. O entendimento do migrante como um sujeito que traz em sua vivência possibilidades concreta de melhoria das condições de vida e dinamização das economias locais deve ser levado em conta.

\section{REFERÊNCIAS}

ARAÚJO, Daniel Féo Castro de. O lado amargo da cana: estudos sobre trabalhadores migrantes no setor sucroenergético no pontal do triângulo mineiro. 2018. Dissertação (Mestrado em Ciências Sociais) - Instituto de Ciências Sociais, Universidade Federal de Uberlândia, MG, Uberlândia, 2018.

ARAÚJO, Daniel Féo Castro de; ARAÚJO SOBRINHO, Fernando Luiz. A cultura agrícola da cana-de-açúcar no Brasil: contribuição ao estudo dos territórios rurais e suas contradições e 
conflitos. Geopauta, Vitória da Conquista, BA, v. 4, n. 1, p. 162-183, abr. 2020. Disponível em: http://periodicos2.uesb.br/index.php/geo/article/view/6303. Acesso em: 30 jun. 2020.

ARENDT, Hannah. Origens do totalitarismo. São Paulo: Companhia das Letras, 2007.

BACCARIN, José Giacomo. A constituição da nova regulamentação sucroalcooleira. São Paulo, SP: UNESP; Brasília, DF: UnB, 2002.

BOSI, Ecléa. Cultura e desenraizamento: cultura brasileira: temas e situações. São Paulo: Ática, 1992.

CLEPS JÚNIOR, João. Concentração de poder no agronegócio e (des)territorialização: os impactos da expansão recente do capital sucroalcooleiro no Triângulo Mineiro. Caminhos de Geografia, Uberlândia, MG, v. 10, n. 31, p. 249-264, 2009.

D'AQUINO, Teresinha. Nas Terras de Promissão: da luta à construção do 'lugar'. Marília: UNESP, 1998. Relatório de Pesquisa, v. 1, n. 1, p. 1-18.

DURHAM, Eunice Ribeiro. A caminho da cidade. A vida rural e a migração para São Paulo. São Paulo: Perspectiva, 1984.

FONSECA, Rogério Gerolineto; SANTOS, Joelma Cristina dos. Os recentes processos migratórios em Ituiutaba (MG) e a inserção das agroindústrias canavieiras. Caderno

Prudentino de Geografia, Presidente Prudente, SP, v. 1, n. 33, p. 24-49, jul. 2011. Disponível em: http://agbpp.dominiotemporario.com/doc/33A-3.pdf. Acesso em: 20 mar. 2020.

IBGE. Cidades. Ituiutaba - MG. Contagem da população- 2014. Rio de Janeiro, RJ: IBGE, 2014. Disponível em: \&lt;www.ibge.gov.br./cidadesat/topwindonw.htm\&gt. Acesso em: 6 jul. 2020.

LAGO, Paulo Cesar do. Participação popular e reforma urbana: da constituinte ao estatuto da cidade. 2010. Dissertação. (Mestrado em Direito Político e Econômico) Universidade Presbiteriana Mackenzie, 2010.

MATOS, Patrícia Francisca de; FRATARI, Marina Franco; CARVALHO, Rogério Gonçalves de. Fim do corte manual da cana-de-açúcar na microrregião de Ituiutaba (MG) e os impactos para os trabalhadores. Caminhos de Geografia, Uberlândia, v. 19, p. 194-203, 2018. Recurso online.

MENEZES, Marilda Aparecida de. Da Paraíba prá São Paulo e de São Paulo prá Paraíba: migração, família e reprodução da força de trabalho. 1985. Dissertação (Mestrado em Sociologia) - Universidade Federal da Paraíba, Campina Grande, PB, 1985.

PEIXOTO, João. As teorias explicativas das migrações: teorias micro e macrosociológicas. Lisboa, PT: SOCIUS - Centro de Investigação em Sociologia Econômica das Organizações, Instituto Superior de Economia e Gestão, Universidade Técnica de Lisboa. 2004. (SOCIUS Working Papers, n. 11).

PESSÔA, Vera Lúcia Salazar. Ação do estado e as transformações agrarias no Cerrado das Zonas de Paracatu e Alto Paranaíba - MG. Rio Claro, SP: IGCE/UNESP, 1988.

RAMOS, Nilza Patrícia; LUCHIARI JÚNIOR, Ariovaldo. Cana-de-açúcar: setor sucroalcooleiro. Ageitec - Agência Embrapa de Informação Tecnológica, Campinas, SP, 2008. Árvore do Conhecimento. Cana-de-açúcar. Disponível em:

http://www.agencia.cnptia.embrapa.br/gestor/cana-de-acucar/arvore/CONT1.html. Acesso em: 21 mar. 2020.

RIBEIRO, Hidelberto de Sousa. O migrante e a cidade: dilemas e conflitos. 2000. Tese (Doutorado em Sociologia) - Departamento de Sociologia, Instituto de Filosofia e Ciências Humanas, Universidade Estadual Paulista, Araraquara, SP, 2000. 
SILVA, Dalva M. de O. Memória: lembrança e esquecimento: trabalhadores nordestinos no Pontal do Triângulo Mineiro nas décadas de 1950 e 1960. 1997. Dissertação (Mestrado em História) - São Paulo, Pontifícia Universidade Católica - PUC - SP, São Paulo, SP, 1997.

SILVA, Luiz Carlos Santos da; SANTOS, Joelma Cristina dos. A cana-de-açúcar e o trabalho precário nas agroindústrias canavieiras da microrregião geográfica de Ituiutaba (MG). In: CONGRESSO IBERO AMERICANO DE ESTUDIOS TERRITORIALES Y AMBIENTALES, 6., São Paulo, SP, 2014. Anais [...]. São Paulo: USP, 2014. p. 2169-2188. Disponível em: https://docplayer.com.br/35964172-A-cana-de-acucar-e-o-trabalho-precario-nasagroindustrias-canavieiras-da-microrregiao-geografica-de-ituiutaba-mg.html. Acesso em: 5 mar. 2020.

SILVA, Maria Aparecida de Moraes. Contribuições metodológicas para análise das migrações. In: HEIDEMANN, Heinz Dieter; SILVA, Sidney Antônio da. Migração: nação, lugar e dinâmicas territoriais. São Paulo: Associação Editorial Humanitas, 2007. p. 67-78.

SILVA, Silvano de Cássio da; SANTOS, Joelma Cristina dos. A mão de obra temporária migrante empregada nas agroindústrias canavieiras no município de Ituiutaba-MG e seus impactos no comércio local. Horizonte Científico, Uberlândia, MG, v. 9, n. 2, p. 1-20, dez. 2015. Disponível em: http://www.seer.ufu.br/index.php/horizontecientifico/article/view/31120. Acesso em: 20 fev. 2020.

SINGER, Paul. Migrações internas: considerações teóricas sobre o seu estudo. In: SINGER, P. Economia politica da urbanização. São Paulo: Contexto,1998. p. 29 - 62.

WEIL, Simone. O desenraizamento operário. In: BOSI, Ecléa. (org.). A condição operária e outros estudos sobre a opressão. Rio de Janeiro, RJ: Paz e Terra, 1996. p. 413-440.

Recebido: abril de 2020.

Aceito: julho de 2020. 